\title{
The Use of Vasoconstrictors in Acute Variceal Bleeding: How Long Is Enough?
}

\author{
Gin-Ho Lo \\ Division of Gastroenterology, Department of Medical Research, E-DA Hospital, Kaohsiung, Taiwan
}

\begin{abstract}
Vasoconstrictors are often used as the first line therapy for acute esophageal variceal hemorrhage. They might also be used for a few days after endoscopic therapy to prevent early rebleeding. International guidelines recommend the use of vasoconstrictor therapy when acute esophageal variceal hemorrhage is suspected and continuation of the therapy until 3 to 5 days after endoscopic treatment. However, the duration of use of vasoconstrictors after endoscopic therapy is not clear. This review shows that if variceal bleeding is successfully controlled by endoscopic variceal ligation, the combination of vasoconstrictors can be reduced to less than 1 day.

Clin Endosc 2019;52:36-39
\end{abstract}

Key Words: Acute variceal bleeding; Sclerotherapy; Vasoconstrictors; Banding ligation

\section{INTRODUCTION}

Acute esophageal variceal hemorrhage $(\mathrm{AEVH})$ is a major complication of portal hypertension. Previous reports have indicated that AEVH is associated with a mortality rate of $40 \%$, and a high incidence of early rebleeding in the survivors, with an incidence of $30 \%$ to $50 \% .{ }^{1}$ Fortunately, the mortality rate due to AEVH has significantly reduced in the last 2 decades. $^{2-4}$ The first introduction of vasoconstrictor therapy in the treatment of variceal hemorrhage was around 1970. Since then, vasoconstrictors have played an important role in the management of AEVH. Subsequently, endoscopic injection sclerotherapy (EIS) became widely popular in the treatment of AEVH. However, EIS alone is still associated with a high incidence of early rebleeding. Thus, a few studies have investigated the efficacy of a combination of endoscopic therapy and vasoconstrictors in the control of acute variceal bleeding. ${ }^{5-7}$

Received: May 24, 2018 Accepted: June 7, 2018

Correspondence: Gin-Ho Lo

Division of Gastroenterology, Department of Medical Research, E-DA Hospital, 1, Yi-Da Road, Kaohsiung 824, Taiwan

Tel: +886-7-615-0011-5186, Fax: +886-7-615-0940, E-mail: ghlo@kimo.com ORCID: https://orcid.org/0000-0001-7190-200X

cc This is an Open Access article distributed under the terms of the Creative Commons Attribution Non-Commercial License (http://creativecommons.org/ licenses/by-nc/3.0) which permits unrestricted non-commercial use, distribution, and reproduction in any medium, provided the original work is properly cited.
Some studies showed that a combination of EIS and vasoconstrictors could achieve a higher hemostatic rate. ${ }^{8}$ A meta-analysis of 8 trials in 2003 including 939 patients, demonstrated that the 5 -day hemostasis rate was $58 \%$ in patients receiving endoscopic therapy alone, while the corresponding figure was $77 \%$ in patients receiving a combination therapy, with similar rates of survival and severe adverse events in both groups. Thus, the combination of endoscopic therapy and vasoconstrictors in the management of AEVH has been recommended by nearly all the hepatology and endoscopy guidelines. ${ }^{2,4,10,11}$ Continuous use of vasoconstrictors following endoscopic therapy for 3-5 days has become a routine in clinical practice. ${ }^{11}$ However, the meta-analysis by Bañares et al. included 3 full-texts and 3 abstracts about EIS therapy, 1 fulltext in which both EIS and endoscopic variceal ligation (EVL) were used and 1 full-text paper in which EVL was used as an endoscopic therapy. ${ }^{9,11}$ Since EVL has now replaced EIS as the endoscopic therapy of choice to treat $\mathrm{AEVH},{ }^{4,12}$ it is necessary to understand the duration for which should the combination of vasoconstrictors be continued following successful EVL. ${ }^{13,14}$ Thus, this review tries to analyze the studies conducted with EIS alone versus EIS plus vasoconstrictors and EVL alone versus EVL plus vasoconstrictors respectively, to establish the role of vasoconstrictors as an adjunct to endoscopic therapy in AEVH. 


\section{COMBINATION OF SCLEROTHERAPY AND VASOCONSTRICTORS}

Only 6 full-text articles comparing EIS alone and EIS with vasoconstrictors in the management of AEVH have been found so far (Table 1). 5, ${ }^{5,15-18}$ Possibly owing to the introduction of EVL, studies using a combination of EIS and vasoconstrictors have not been reported after 2005. Although terlipressin is the only vasoactive drug known to increase survival in patients with AEVH, none of the 6 trials used terlipressin as an adjunct therapy. Among the 6 studies, 4 used octreotide, 1 study used somatostatin ${ }^{15}$ and 1 study used vapreotide, an analogue of somatostatin. ${ }^{17}$ The duration of vasoconstrictor therapy ranged from as short as 48 hours $^{18}$ to as long as 29 days. ${ }^{6}$ The study by Calés et al. included approximately $30 \%$ of the patients who underwent EVL as an endoscopic therapy. ${ }^{17}$ The study by Primignani et al. did not indicate the rate of acute hemostasis but showed early rebleeding at 15 days. ${ }^{6}$ As shown in Table 1, the rate of hemostasis achieved by EIS alone was between $46 \%$ and $78.1 \%$, while that achieved with combination therapy ranged between $66 \%$ and $88 \%$. All the 6 trials except the study by Primignani et al., proved the superiority of combining EIS and vasoconstrictors over EIS alone, in the control of AEVH. ${ }^{6}$ However, the rate of hemostasis with EIS alone in all these trials was quite lower than that in other studies. ${ }^{19}$ This could explain the superiority of combining endoscopic therapy with vasoconstrictors. On the other hand, a combination of EIS with vasoconstrictors did not improve the survival over EIS alone.

\section{COMBINATION OF BANDING LIGATION AND VASOCONSTRICTORS}

Since EVL has replaced sclerotherapy as the endoscopic therapy of choice for $\mathrm{AEVH},{ }^{12}$ a combination therapy with EVL and vasoconstrictors has become popular in recent years. Sung et al. was the first to prove that a combination of EVL and octreotide was superior to EVL alone in the management of AEVH. ${ }^{7}$ However, the hemostasis rate achieved by EVL was only $56 \%$, significantly lower than that seen in most other studies. ${ }^{4,12,13}$ Thus, the combination of EVL with

Table 1. Comparison of Acute Hemostasis between Sclerotherapy Alone versus Sclerotherapy Plus Vasoconstrictors

\begin{tabular}{|c|c|c|c|}
\hline Study & Sclerotherapy alone & Sclerotherapy+Octreotide & Sclerotherapy+Somatostatin \\
\hline Besson et al. $(1995)^{5}(n=199)$ & $71 \%$ & $87 \%$ & \\
\hline Primignani et al. $(1995)^{6}(n=58)^{\mathrm{a})}$ & $78.1 \%$ & $80.8 \%$ & \\
\hline Avgerinos et al. $(1997)^{15}(n=205)$ & $46 \%$ & & $66 \%$ \\
\hline Zuberi et al. $(2000)^{16}(n=70)$ & $62.8 \%$ & $88.6 \%$ & \\
\hline Calès et al. $(2001)^{17}(n=196)^{\mathrm{b})}$ & $50 \%$ & & $66 \%$ \\
\hline Shah et al. $(2005)^{18}(n=105)$ & $61.1 \%$ & $86.2 \%$ & \\
\hline
\end{tabular}

a) The hemostatic rate shown was at day 15 .

${ }^{b)}$ Enrolled subjects about 50\% received sclerotherapy, 30\% received ligation; Patients received vapreotide instead of somatostatin.

Table 2. Variceal Bleeding Controlled with Banding Ligation Alone or Combined with Pharmacological Therapy

\begin{tabular}{|c|c|c|c|c|}
\hline Study & $\begin{array}{l}\text { Ligation } \\
\text { alone }\end{array}$ & $\begin{array}{c}\text { Ligation } \\
+ \text { Octreotide }\end{array}$ & $\begin{array}{c}\text { Ligation } \\
+ \text { Somatostatin }\end{array}$ & $\begin{array}{c}\text { Ligation } \\
+ \text { Terlipressin }\end{array}$ \\
\hline Sung et al. $(1995)^{7}(n=100)$ & $56 \%$ & $87 \%$ & & \\
\hline Lo et al. $(1997)^{13}(n=37)$ & $97 \%$ & & & \\
\hline Villanueva et al. $(2006)^{20}(n=90)$ & & & $90 \%$ & \\
\hline Abid et al. $(2009)^{21}(n=324)$ & & $95.6 \%$ & & $92.6 \%$ \\
\hline Azam et al. $(2012)^{22}(n=130)$ & & & & $98.5 \%^{\mathrm{a})} / 100 \%^{\mathrm{b})}$ \\
\hline Lo et al. $(2013)^{24}(n=118)$ & $98 \%$ & & & $96 \%$ \\
\hline Seo et al. $(2014)^{23}(n=780)$ & & $83.8 \%$ & $83.4 \%$ & $86.2 \%$ \\
\hline Salim et al. $(2017)^{25}(n=67)$ & $95.1 \%$ & - & - & - \\
\hline
\end{tabular}

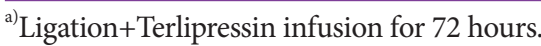

${ }^{b)}$ Ligation+Terlipressin infusion for 24 hours. 
vasoconstrictors can potentially enhance the efficacy in hemostasis. Since controlled studies comparing EVL alone and the combination of vasoconstrictors with EVL are quite few, Table 2 shows some related figures of similar studies. Our study comparing EVL and EIS alone in the control of active bleeding varices showed that EVL alone could arrest $97 \%$ of the bleeding episodes. ${ }^{13}$ Similarly, Villanueva et al. showed that the use of somatostatin with EVL instead of sclerotherapy in the treatment of AEVH significantly improved the hemostasis rate up to $90 \% .^{20}$ Regarding the choice of vasoconstrictors, one study showed that terlipressin was not inferior to octreotide as an adjuvant therapy with EVL for the control of AEVH, i.e., $92.6 \%$ vs. $95.6 \%{ }^{21}$ Moreover, a study from Egypt showed that a short course of adjuvant terlipressin (i.e., 24 hours) was as effective as a 72 hour therapy with successful EVL in achieving a rate of acute hemostasis of $100 \%$ and $98.5 \%$, respectively. ${ }^{22}$ Another study from Korea also showed no difference between terlipressin, somatostatin and octreotide as an adjuvant to EVL with the 5-day hemostasis rate of AEVH being 86.2\%, $83.4 \%$ and $83.8 \%$, respectively. ${ }^{23}$ Since ligation ulcers are frequently encountered in patients receiving EVL, we performed a study to evaluate proton pump inhibitor versus terlipressin as an adjunctive therapy to patients with successful EVL. ${ }^{24}$ Our trial showed that EVL with proton pump inhibitor (without vasoconstrictors) could achieve a $98 \%$ hemostasis rate, similar to $96 \%$ achieved by EVL plus terlipressin. In a single arm study, Salim et al. demonstrated that EVL alone could achieve an acute hemostasis rate of $95.1 \% .{ }^{25}$ Based on these studies, it is clear that EVL alone can achieve an acute hemostasis rate ranging between $56 \%$ and $98 \%$. The corresponding rates with a combination of EVL and vasoconstrictors were between $83.4 \%$ and $100 \%$. In fact, only the first study by Sung et al. in 1995 showed that EVL alone achieved an acute hemostasis rate as low as $56 \%{ }^{7}$ Most other studies revealed that EVL alone could achieve acute hemostasis up to $90 \% .^{12,13,24,25}$

\section{OPTIMAL DURATION OF VASOCONSTRICTOR THERAPY}

For a long time, vasoconstrictors have been considered as the best adjuvant to endoscopic therapy, to arrest AEVH. The rationale of combining vasoconstrictors with endoscopic therapy is to reduce the portal pressure and variceal blood flow as a preventive for very early rebleeding. Both the meta-analyses published between 1999 and 2003 showed that a combination of vasoconstrictors and endoscopic therapy was superior to endoscopic therapy alone in the control of AEVH. ${ }^{8,9}$ However, both meta-analyses included trials that mostly used EIS as an endoscopic therapy. Since EIS is associated with a high incidence of rebleeding, EIS should be combined with vasoconstrictors to achieve a higher rate of hemostasis. Even with a combination of vasoconstrictors, the successful 5-day hemostasis with EIS was only in the range of $66 \%$ and $88 \%$. By contrast, EVL alone appears to be as effective as the combination of vasoconstrictors and EVL in the control of AEVH. Additionally, no difference was found between the combination of vasoconstrictors such as octreotide, somatostatin or terlipressin with EVL. It can thus be construed that all 3 vasoconstrictors are equally efficient as an adjunct therapy to EVL. ${ }^{26}$

It is now recommended that vasoconstrictors should be administered when an episode of AEVH is suspected. It is also believed that vasoconstrictors should be continued for $2-5$ days after endoscopic therapy.2, ${ }^{2,10,11}$ For example, 2 mg of terlipressin every 4 hours in the initial 48 hours until control of bleeding is recommended, followed by $1 \mathrm{mg}$ every 4 hours for another 3 days to prevent rebleeding. ${ }^{11}$ Though vasoconstrictors other than vasopressin are generally considered quite safe, terlipressin is associated with multiple and moderately severe adverse events. ${ }^{24}$ Combination with vasoconstrictors up to 5 days after successful EVL increases medical the expenditure and adverse events, with the likelihood of an increase in the hospitalization days. It has been found that the rebleeding is most likely to occur in the first 5 days after AEVH; ${ }^{27}$ thus, a longer duration of treatment with vasoactive drugs is considered as a practical approach. However, most studies revealed that EVL alone could achieve acute hemostasis in more than $95 \%$ of the cases, ${ }^{12,13}$ with a rebleeding rate of $5 \%$ in one month. ${ }^{13}$ Consequently, the combination with vasoconstrictors up to 5 days after EVL might be indicated only in endoscopic therapy failure cases. Once EVL has achieved a successful hemostasis on endoscopy, the combination of vasoconstrictors for only 24 hours $^{22}$ or discontinuation of vasoconstrictors soon after endoscopic therapy, does not seem to increase the risk of rebleeding. ${ }^{13,24,25}$ It is necessary to conduct a head to head comparison study between EVL alone and EVL combination therapy with vasoconstrictors in the therapy of AEVH. However, EVL alone to treat AEVH would be considered unethical, since all related guidelines recommend that EVL should be combined with vasoconstrictors to treat $\mathrm{AEVH} .^{10,11}$ If vasoconstrictors can be discontinued early in the management of AEVH, beta blockers can be instituted earlier to prevent variceal bleeding. ${ }^{28}$ On the other hand, for patients belonging to Child-Pugh class $\mathrm{C}$ or hepatic venous pressure gradient $\geq 20 \mathrm{~mm} \mathrm{Hg}$, a high risk of rebleeding is observed. ${ }^{29}$ Combination with vasoconstrictors for up to 5 days and early transjugular intrahepatic portosystemic stent shunt in this setting might be indicated. ${ }^{30}$ 


\section{CONCLUSIONS}

Vasoconstrictors should be administered when AEVH is suspected. It is mandatory to continue vasoconstrictor therapy for up to 5 days if an EIS is performed to arrest the AEVH. If EVL is performed to treat the bleeding varices, the combination therapy with vasoconstrictors can be shortened to 24 hours or discontinued soon after successful ligation of the bleeding varices on endoscopy. Combination therapy with vasoconstrictors up to 5 days could be used for patients who fail to respond to EVL therapy. These would be approximately $5 \%-15 \%$ of patients undergoing EVL to treat AEVH.

\section{Conflicts of Interest}

The author has no financial conflicts of interest.

\section{REFERENCES}

1. Graham DY, Smith JL. The course of patients after variceal hemorrhage. Gastroenterology 1981;80:800-809.

2. Garcia-Tsao G, Sanyal AJ, Grace ND, Carey W. Prevention and management of gastroesophageal varices and variceal hemorrhage in cirrhosis. Hepatology 2007;46:922-938.

3. Lo GH, Chen WC, Chen MH, et al. The characteristics and the prognosis for patients presenting with actively bleeding esophageal varices at endoscopy. Gastrointest Endosc 2004;60:714-720.

4. Laine L, Planas R, Nevens F, Banares R, Patch D, Bosch J. Treatment of the acute bleeding episode. In: de Franchis R, ed. Portal hypertension IV - proceedings of the 4th Baveno International Consensus Workshop. Oxford: Blackwell Publishing; 2006. p. 217-242.

5. Besson I, Ingrand P, Person B, et al. Sclerotherapy with or without octreotide for acute variceal bleeding. N Engl J Med 1995;333:555-560.

6. Primignani M, Andreoni B, Carpinelli L, et al. Sclerotherapy plus octreotide versus sclerotherapy alone in the prevention of early rebleeding from esophageal varices: a randomized, double-blind, placebo-controlled, multicenter trial. New Italian Endoscopic Club. Hepatology 1995;21:1322-1327.

7. Sung JJ, Chung SC, Yung MY, et al. Prospective randomised study of effect of octreotide on rebleeding from oesophageal varices after endoscopic ligation. Lancet 1995;346:1666-1669.

8. de Franchis R, Primignani M. Endoscopic treatments for portal hypertension. Semin Liver Dis 1999;19:439-455.

9. Bañares R, Albillos A, Rincón D, et al. Endoscopic treatment versus endoscopic plus pharmacologic treatment for acute variceal bleeding: a meta-analysis. Hepatology 2002;35:609-615.

10. Tripathi D, Stanley AJ, Hayes PC, et al. U.K. guidelines on the management of variceal haemorrhage in cirrhotic patients. Gut 2015;64:16801704.

11. Garcia-Tsao G, Abraldes JG, Berzigotti A, Bosch J. Portal hypertensive bleeding in cirrhosis: risk stratification, diagnosis, and management: 2016 practice guidance by the American Association for the study of liver diseases. Hepatology 2017;65:310-335.

12. Laine L, Cook D. Endoscopic ligation compared with sclerotherapy for treatment of esophageal variceal bleeding. A meta-analysis. Ann Intern Med 1995;123:280-287.

13. Lo GH, Lai KH, Cheng JS, et al. Emergency banding ligation versus sclerotherapy for the control of active bleeding from esophageal varices. Hepatology 1997;25:1101-1104.

14. Lo GH. Do we need vasoconstrictors up to 5 days after successful hemostasis by ligation of bleeding varices? Hepatology 2017;66:1009.

15. Avgerinos A, Nevens F, Raptis S, Fevery J. Early administration of somatostatin and efficacy of sclerotherapy in acute oesophageal variceal bleeds: the European Acute Bleeding Oesophageal Variceal Episodes (ABOVE) randomised trial. Lancet 1997;350:1495-1499.

16. Zuberi BF, Baloch Q. Comparison of endoscopic variceal sclerotherapy alone and in combination with octreotide in controlling acute variceal hemorrhage and early rebleeding in patients with low-risk cirrhosis. Am J Gastroenterol 2000;95:768-771.

17. Calès P, Masliah C, Bernard B, et al. Early administration of vapreotide for variceal bleeding in patients with cirrhosis. N Engl J Med 2001;344:23-28.

18. Shah HA, Mumtaz K, Jafri W, et al. Sclerotherapy plus octreotide versus sclerotherapy alone in the management of gastro-oesophageal variceal hemorrhage. J Ayub Med Coll Abbottabad 2005;17:10-14.

19. Paquet KJ, Feussner H. Endoscopic sclerosis and esophageal balloon tamponade in acute hemorrhage from esophagogastric varices: a prospective controlled randomized trial. Hepatology 1985;5:580-583.

20. Villanueva C, Piqueras M, Aracil C, et al. A randomized controlled trial comparing ligation and sclerotherapy as emergency endoscopic treatment added to somatostatin in acute variceal bleeding. J Hepatol 2006;45:560-567.

21. Abid S, Jafri W, Hamid S, et al. Terlipressin vs. octreotide in bleeding esophageal varices as an adjuvant therapy with endoscopic band ligation: a randomized double-blind placebo-controlled trial. Am J Gastroenterol 2009;104:617-623.

22. Azam Z, Hamid S, Jafri W, et al. Short course adjuvant terlipressin in acute variceal bleeding: a randomized double blind dummy controlled trial. J Hepatol 2012;56:819-824.

23. Seo YS, Park SY, Kim MY, et al. Lack of difference among terlipressin, somatostatin, and octreotide in the control of acute gastroesophageal variceal hemorrhage. Hepatology 2014;60:954-963.

24. Lo GH, Perng DS, Chang CY, Tai CM, Wang HM, Lin HC. Controlled trial of ligation plus vasoconstrictor versus proton pump inhibitor in the control of acute esophageal variceal bleeding. J Gastroenterol Hepatol 2013;28:684-689.

25. Salim A, Amin MJ, Javed M, et al. Terlipressin administered only prior to endoscopic therapy in the management of bleeding esophageal varices does not increase the risk of re-bleeding compared to standard 3-5 days regime. Annals of Punjab Medical College 2017;11:78-82.

26. Lo GH. Lack of difference among vasoconstrictors: similar effectiveness or similar ineffectiveness? Hepatology 2015;62:653.

27. de Franchis R. Longer treatment with vasoactive drugs to prevent early variceal rebleeding in cirrhosis. Eur J Gastroenterol Hepatol 1998;10:1041-1044.

28. Lo GH, Lai KH, Cheng JS, et al. Endoscopic variceal ligation plus nadolol and sucralfate compared with ligation alone for the prevention of variceal rebleeding: a prospective, randomized trial. Hepatology 2000;32:461-465.

29. Moitinho E, Escorsell A, Bandi JC, et al. Prognostic value of early measurements of portal pressure in acute variceal bleeding. Gastroenterology 1999;117:626-631.

30. García-Pagán JC, Caca K, Bureau C, et al. Early use of TIPS in patients with cirrhosis and variceal bleeding. N Engl J Med 2010;362:2370-2379. 